\title{
Sommaire
}

Carole Reynaud Paligot

Perspectives pour une histoire comparée des pensées raciales

Armelle ENDERS

Du pessimisme à l'optimisme. Les métamorphoses de la pensée raciale

au Brésil et la réception des théories de Gilberto Freyre (1890-1930)

Albert GOUAFFo

Du racisme scientifique au racisme populaire. De la contribution des Camerounais au profil racial de l'Allemagne impériale (1884-1919)

Mamoudou SY

»Peuplades « ou descendants de chorfas? Représentations au XIX $\mathrm{e}^{\mathrm{e}}$ siècle des peuples de la Sénégambie septentrionale

Arnaud NANTA

Kiyono Kenji: Anthropologie physique et débats sur la »race japonaise«

à l'époque de l'empire colonial (1920-1945)

Marc SCHINDLER-BONDIGUEL

Auxiliaires indigènes ou soldats français? Race, civilisation et genre dans la construction d'une catégorie impériale: le soldat indigène. L'exemple des soldats malgaches (1889-1939)

Céline TrautmanN-Waller

Langue, peuple, race, nation: usages de la notion de race, frontières disciplinaires et enjeux politiques chez les philologues en France et en Allemagne durant la deuxième moitié du XIX ${ }^{\mathrm{e}}$ siècle

\section{Agnès GRACEFFA}

La tentation de la pensée raciale dans les lectures historiographiques françaises et allemandes 1920-1930 du peuplement dit germanique de la Gaule: une conception historique de la race

\section{Benoît LARBIOU}

Le corps médical et la race en 1930. Les usages médicaux du racialisme

Index des personnes 
